\title{
Impact of ERP Implementation on Productivity and Profitability: An Empirical Study on the Largest Bangladeshi Steel Manufacturer
}

\author{
Mohammad Rokibul Kabir ${ }^{*}$ \\ ${ }^{1}$ Associate Professor, East Delta University, Chittagong, Bangladesh and Post-Doctoral Research Fellow, Universiti Malaysia Perlis, Malaysia.
}

* Corresponding author: rokibul.k@eastdelta.edu.bd

\begin{abstract}
Submission: 04 August 2020 Abstract

Revised: 24 September 2020

Published: 29 November 2020

The research aims to evaluate the impact of Enterprise Resources Planning (ERP) implementation on the productivity and profitability of BSRM Steels Limited. The study focuses on addressing the gap in technology adoption literature by undertaking an empirical comparison of the impact of ERP implementation. Five productivity variables called service time, lead time, inventory turnover, output-input ratio, and warehouse cost are evaluated. Gross Profit Margin represents profitability as ERP is mainly implemented in the inventory management system of BSRM. Paired sample t-tests between the pre and post ERP performances have been used to evaluate the impact of ERP. Ten years' data ranging from 2010 to 2019 have been considered for the study. Five years' data (2010-2014) consist of before ERP period, and the other five years' data (2015-2019) represent after ERP implementation period. The study reveals that both the productivity and profitability of BSRM have significantly improved after ERP implementation. This paper will have an impactful contribution to the academic literature of technology adoption in the manufacturing sector, particularly for ERP implementation in the steel industry of Bangladesh, which could be supportive for further study on the topic.
\end{abstract}

Keywords: Bangladesh, BSRM Steels Ltd., ERP, Productivity, Profitability

\section{INTRODUCTION}

Bangladesh is a developing country with a growing degree of industrial advancements. The nation has seen a gradual growth in the industrial development index in the last couple of decades (Hasan, Hoq, \& Thollander, 2018). Bangladesh is one of the largest Asian steel users. It is increasingly in need of steel-making innovation. Compared to the country's estimated growth as an industrialized entity, this sector itself is expected to advance at a rate of more than 15\% (Bangladesh Steel Industry Analysis, 2016). The steel sector of the country is well-structured that supplies domestic and foreign exports. In comparison with 2012, the country's steel sector's production capacity has become above three times in 2015. The demand for steel is anticipated to become twice in 2022 (LightCastle Partners, 2016). The steel industry's output potential in Bangladesh grew from a modest 47,000 MT in 1971 to 4.0 million MT in 2015 (Bangladesh Steel Industry Review, 2016). The steel demand is motivated primarily by two factors. One of which is the government's 'Annual Development Program' (ADP) policies and infrastructure construction initiatives. The other is demand for both the industrial and personal usages, particularly for the real estate market. Big companies are investing freshly in this sector to expand their output capability to catch the promise of the tremendous demand to execute large government infrastructure development plans. As a result, there is a technological change in the steel industry. Simultaneously, the availability of raw materials, transportation, port facilities, and effective inventory management of finished goods remains critical for the industry. Steel processing firms are now searching for ERP solutions to streamline their operations and shift from manual processes to electronic information management systems for the highest efficiency and smooth operation. Brazel \& Dang (2008) examined ERP systems and found that it has become the system of choice for most of the steel manufaturing companies. The ERP has radically changed the way production processes and accounting information is processed, prepared, audited, and disseminated. In this paper, we investigated how the introduction of the ERP program has changed the degree to which companies control productions for a better productivity. In a group of ERP adopters, they observed that adoption contributed to an improvement in gross accruals' actual valuation (i.e., better earnings management).

For leaner and more productive production processes, many steel companies leverage advanced business process technology to minimize costs and thus increase profitability. BSRM Steels Ltd. launched its ERP program in mid-2014 to reduce production costs through increased flexibility and alignment of approaches and operations to handle its company-wide activities and business processes. The purpose of this study is to examine whether the introduction of the ERP program would bring any significant positive improvements to BSRM Steels Limited's productivity and profitability.

\section{Overview of BSRM Steel Limited}

Bangladesh Steel Re-Rolling Mills, usually referred to as BSRM, is a Bangladeshi steel manufacturing firm located in Chittagong. It's the oldest re-rolling steel mill in Bangladesh. The BSRM Group started its journey in 1952 with a set of 4 small manual rolling mills in Nasirabad, 
Chittagong. It was the first steel mill in the country. Over the years, the BSRM Group of Companies has gradually expanded. The four old manual mills were scrapped, and adopting new technology, an automatic billet-based cross country European rolling mill was installed. In 1984, Akberali Africawala (founder of the group) and Alihussain Akberali (current chairman of BSRM) purchased a second-hand automated re-rolling mill from the UK for the BSRM factory in Chittagong. They thereby introduced high strength cold twisted steel bars (TORSTEL) to the construction industry. In 1996, the company installed a captive ticket producing plant to ensure the constant delivery of premium tickets to its rolling mills. In 2006, the first and only cold-rolling wire ribbed plant in the world started operations utilizing European technologies to manufacture $500 \mathrm{MPA}$ of $4.5 \mathrm{~mm}, 5.7 \mathrm{~mm}$, and $7.1 \mathrm{~mm}$ wire protection reinforcements, significantly reducing construction costs.

Today, BSRM is the most prominent merchant steel producing company in Bangladesh, regarded as the country's best-managed steel units. Similarly, The BSRM Group is the oldest and most prominent business group in Bangladesh's steel industry.

BSRM Steels Limited (BSRMS), a concern of the BSRM and the first listed company under the group's umbrella, incorporated in Bangladesh's stock exchanges on 18th January, 2009. It is the leader of the industry. A German consultant and Danieli Company planned the project, Italy supplied the full mill. The business has been commercially operating since 1st April 2008. Today, BSRM Steels Limited is the largest steel manufacturer in the country with a capacity of 800,000 metric tons (MT) of deformed bars and plates. As of the fiscal year 20172018, the company sold 710,995 MT of finished products against budgeted sales of 655,000 MT and has made sales revenue of TK. 48,289.92 Million, while net profit stood at TK. 1.80 Billion for the period.

In 2014, the Oracle ERP system was implemented by BSRM Steels Limited to maintain inventory records and balance sheets, monitor various product payments, and retain costing data. Before that, BSRM used to use IBMS (integrated business management suite). IBMS is an off the shelf, modular platform limited to just three different modules-Sales, Delivery \& Weighing Scale. Since the BSRM Group has several sister concerns in the field of steel recycling to melting, producing billets for re-rolling, it has been critical for the company to integrate its entire operation into a holistic business process system that can replace multiple databases with a single centralized data source, With inventory sales, materials and suppliers information available to anyone in a company. That's why BSRM has chosen Oracle EBS that includes full integration of inventory assets with other related ERP modules such as Oracle Landed Cost Management, Purchasing, Process Processing, Order Management, General Ledger, and Enterprise Asset Management. BSRM integrated details of internal and external information on inventory items and the status of material transactions throughout the organization with Oracle EBS.

\section{LITERATURE REVIEW}

This segment consists of a review of the previous literature in the domain of ERP adoption in manufacturing industries. Here we will discuss the research done by different scholars regarding the effect of the implementation of the ERP in manufacturing firms in various countries around the world.

Bagranoff and Brewer (2003) conducted a case study where the Amscot division was put in charge of printing, assembling, and distributing all printed materials related to its commercial services and investment for all its valued customers. Amscot adopted an ERP system to house all production, commercial, human resource, and distribution application under one central database system. Also, real-time information generated from using the ERP system would allow decision making to be more efficient and effective. The ERP system would let fulfillment and delivery process start automatically after receiving customers' orders. Having the entire supply chain coordinated will reduce printed material inventories, minimize excessive shipping costs, and smooth receiving of goods cycle time. Implementation of the ERP could save an estimated $\$ 30$ million annually for the company by reducing unnecessary inventory.

Ross and Vitale (2000) studied the impacts of packaged ERP systems on organizations as a whole. Their main goal was to identify how firms use their ERP environments to create business value. In their research, they deliberately looked for diversity in the ERP packages. Few examples of ERP packages include SAP, Baan, Oracle, and PeopleSoft. Within their research sample, eight firms used SAP, whereas Baan \& Oracle ERP systems were used by three firms, and one firm used PeopleSoft. They selected firms that had gone live with one of the leading ERP packages, either firm-wide or within a firm's significant division. All implementations included manufacturing modules and a combination of financial, sales and marketing, and a few other modules. The sales of these selected firms ranged from $\$ 125$ million to $\$ 25$ billion, and the cost of implementing the ERP packages ranged from $\$ 2$ million to $\$ 130$ million. The implementation time of these ERP packages ranged from 1 to 5 years, which included time from the contract's signing until the final "go-live".

Olhager and Selldin (2003) surveyed the use of ERP systems by Swedish manufacturing firms. The survey mainly focused on ERP system entry, system configuration \& its benefits, pre-implementation process/ implementation experience, and future directions. From the study, they concluded that ERP maturity is high in those firms. Even though the ERP system does not reduce information technology costs, the system rapidly improved the availability \& quality of information and integration \& interactions throughout the firm. The system's highest implementation frequency was seen in modules such as customer order processing and financial management. Performance outcome-related modules such as timely delivery, inventory levels, and cash management had the lowest implementation frequency. Nevertheless, the survey showed that the Swedish firms are ready to adapt/extend their ERP functionality, especially towards supply chain integration.

Yeh and Lin (2007) analyzed the efficacy of introducing the ERP program in enhancing the level of operation in the Taiwanese semiconductor industry. This was done by analyzing the expectation \& perception of service efficiency, including upstream manufacturer and downstream customer's perspective. The result highlighted that the service quality gap exists between upstream manufacturers who use the ERP system and their downstream customers. According to the study, the proposed ERP model provided valuable guidance to manufacturers on preventing, detecting, and eliminating the manufacturing quality gap. Manufacturers further evaluated the ability of various ERP modules in increasing customer satisfaction through service quality by the utilization of the proposed model. It also guided to improve service quality through the elimination of quality gaps.

Poston \& Grabski (2000) examined technology and the firm's performance as a whole, and they mainly focused their research on technological ERP \& its impacts on the firm's performance. They used both economic \& organizational theories to forecast how the ERP system can affect the firm's coordination and transactional costs. Technological ERP would allow (1) reducing the firm's costs through computerization, (2) enabling better decision-making ability through the provision of accurate and timely firm-wide information. Thus, ensuring improvement in the firm's performance. An empiric study was carried out using the financial data archiving of COMPUSTAT companies that have implemented ERP systems and compared them to control the company's counterparts. The results showed a significant increase in costs as a percentage of revenue and a decrease in income for many employees. However, immediately, companies have seen a more substantial reduction in the number of workers. Data suggest a trend that companies with fewer workers promoting more significant sales concurrently report higher cost-to-revenue ratios following the introduction of the ERP. 
Saharia Koch and Tucker (2008) conducted another survey that examined internal auditors' ability to identify \& manage operational, financial, technological, compliance and other risks when the firm shifts to an ERP environment. From this research, it could be deduced that internal auditors recognized a reduction in Financial \& Operational risks, whereas an increase in the firm's technical risks. However, these risks were somewhat diminished through their ability to risk assess \& risk management. Furthermore, their findings highlighted that the internal audit department fulfilled their relevant ERP skills requirement by providing staff with in-house training instead of outsourcing the training programs.

O'Leary's (2004) database from a data repository was used to examine the benefits of ERP systems to find a match between what ERP systems' services are-compared to ERP expectations, thus helping other firms by setting a benchmark when measuring those benefits. A firm's decision to invest in an ERP system is centrally based on the benefits it provides. O'Leary's study revealed that some ERP benefits vary across the industry. In contrast, other services are significant to the firm's independence in any sector. For example, tangible benefits are mainly industry-independent, whereas intangible benefits vary across industries. These findings were statistically consistent with another study conducted by Deloitte Consulting; however, they found more intangible benefits.

Velcu (2007) analyzed the financial advantages of ERP implementation by using an "inside the black box" approach and further examined what business process (BP) improvements are taken place in firms with the alternative reasons for adopting the ERP system (how BP improves influence organizational performance). Velcu's (2007) research is considered an explorative study as it highlighted a relationship between the reason behind the adoption of the ERP and its relative advantages.

Nikolaou (2004) highlighted that organizations could achieve superior financial performance by using information technology when developing business strategies. The popular trend of implementing an ERP system means that firms now have to commit resources towards this. As a result, all aspects of the business operations are affected. The research examines the effects ERP system has on the firm's long term financial performance. The research sample involved large scale data identification \& collection; financial data of 247 firms (before and after ERP implementation) was analyzed. The result showed that firms that implemented ERP systems achieved higher financial performance only after two years of continued use. Effects of ERP system on financial performance was explained by characteristics such as implementation goals, implementation period, and implemented modules \& period.

Rao \& Rao (2009) have reported that information technology, corporate processes, and information exchange significantly affect product turnover efficiency. Their research showed that companies could achieve high inventory turnover by improving internal efficiency (through the removal of non-value added operations and surplus production). Implementation of information technology ERP system would help by providing relevant data on (1) Receipt of goods (2) Sale, Removal or Disposition of products (3) Stock lot \& serial tracking (4) Precise valuation $\&$ status of goods left in inventory at any point of time. Thus, firms can achieve efficient inventory turnover.

Poston and Grabski (2001) examined technology and firm efficiency as a whole; the research focuses on particular technologies like ERP and its effect on firm activities. The theories of economic and industrial organization offer the foundation for analyzing how ERP processes influence business collaboration and transaction expense. ERP programs are supposed to: (1) minimize costs through increasing performance by computerization; and (2) improve decision-making by delivering reliable and relevant enterprise-wide details. Such results can be related to increased firm efficiency. This study revealed no noteworthy improvements in the residual income or ratios between selling $\&$ administrative expenses (taking into account all internal firm variances) over the following three years post ERP system implementation. However, the firm's performance improved significantly as there was a decrease in the cost of goods sold to revenue ratio. This improvement was seen only in year 3 (not year 1 \& 2) post ERP implementation. The employee to revenue ratio also decreased significantly for all three years examined in this study.

Kallunki, Laitinen, and Silvola (2011) conducted a research on the ERP system and focused on the effects of ERP system implementation on financial and non-financial performance. Survey data of 70 businesses were used to conduct empirical analysis. It was found that the management control system (formal type) leads to positive lagged effects between ERP system adoption and non-financial performance. In contrast, informal styles of management control systems show the opposite results. A notable relationship was discovered between financial and non-financial performance. Application of ERP system leads to improved financial returns and management control system help the firm achieve future performance goals than informal types.

Ioannou \& Dimitrio (2012) researched the difficulties associated with dynamically updating manufacturing lead time estimates through manufacturing resource planning (MRP) systems. The proposed approach in this case study allocates an estimated completion time once a new order (with known processing requirements) enters a make-to-order manufacturing system, depending on its current status. This approach involves multiple machinery \& products, the manufacturing sector, which has no particular resource configuration; thus, simple, objectiveoriented iterative algorithms are used instead of fixed lead-time estimates of a typical MRP system. This case study's proposed approach should enable notable improvements compared to the traditional static \& constant MRP lead-time estimates. It also provides evidence of the method's ease of application in real-life Make-To-Order environments.

Hunton, Lippincott, and Reck (2003) researched the longitudinal impact of ERP implementation on the firm's performance. His research used secondary data of 63 firms, collected by Hayes, Hunton, and Reck (2001), and compared a selected firm's performance (that adopted ERP) against others that had not used the ERP system. According to this research findings, financial returns and profitability were way better for firms that used ERP systems compared to those non-adopter firms over three years. These results were somewhat consistent with another case study conducted by Poston and Grabski (2001). This study strengthens the claim that ERP adoption helps the firm achieve a competitive advantage over non-ERP adopters.

Rizzi \& Zamboni (1999) worked on adopting ERP for improving internal logistics efficiency of a manual finished goods warehouse. Their observation revealed that only using an integrated ERP system will not lead to logistics optimization; instead, ERP implementation needs to be done concurrently with redesigning \& reorganization of warehouse logistics and processing. Their study found that to achieve a useful synergistic effect by ensuring higher traceability levels; the entire project should be applied to the final product's manual warehouse.

Matolcsy, Booth, and Wieder (2005) provided evidence on the financial benefit of adopting an ERP system to show the improvements directly derived from the ERP system's execution. Financial and other ratios of a group of companies that implemented ERP systems were compared to another group that did not adapt to the ERP system. The research supports the claim that using of ERP system leads to sustainable production efficiency, improves liquidity position betterment in the receivable management system.

Nicolaou \& Bhattacharya (2006) researched the effects which alterations to the ERP system have on the long-range economic output of firms (that have previously adopted ERP). The impact of individual changes on the post-implementation time frame of the ERP system on the firm's ability to deliver positive long-run financial performance was empirically examined in this study. ERP adopting firms that were previously reviewed by Nicolaou (2004) was chosen as a research sample. 83 out of 247 firms' reported making 182 changes during their ERP system post-implementation period. This research suggested that; modifications to the ERP system often help resolve implementation issues; firms that commence early enhancements (such as add-ons or upgrades to ERP systems) tend to enjoy better differential financial performance than others. Late intensification or abandonment of ERP systems leads to a decline in differential performance for ERP adopting firms. 
According to the hypotheses used in this study, both the nature \& timing of the changes brought to ERP system implementation are essential factors for ERP post-implementation success.

From all contemplate observed within the topic ERP implementation, it is taken note that most of the study focused on various macro issues of both manufacturing and service-based firm and also, majority of the research were conducted in European and Western countries. Very few studies were done in developing Asian countries. Not mindful of studies looking at the impact of ERP implementation on the firm's performance in Bangladesh's steel sector, which inspired the author to study this topic.

\section{Development of Hypotheses}

\section{SERVICE TIME}

Yeh and Lin (2007) explored the efficacy of the ERP implementation in enhancing customer service time in the Taiwanese semiconductor industry by evaluating aspirations and perceptions of customer service time from both upstream suppliers and downstream consumers. The analysis reveals that the suggested model lets suppliers assess various ERP systems' contribution to increasing consumer loyalty with fast response time and offers advice on enhancement approaches to improve service performance by reducing quality gaps.

H1: There is a positive impact of ERP implementation on service quality.

\section{LEAD TIME}

Ioannou and Dimitrio (2012) examined the complex modification of the output lead time calculations used in MRP systems. Once a new order with specific and known processing requirements has entered the manufacturing system, it will be assigned an accurate completion time estimate based on the system's current status. The findings highlight the substantial progress of the new ERP systems over the static MRP leadtime forecasts. The study also supports the ease of application of the technique in real-life make-to-order environments. Based on that following hypothesis has been developed.

$\mathrm{H} 2$ : There is a significant impact of ERP implementation on Lead Time.

\section{INVENTORY TURNOVER}

Rao and Rao (2009) revealed that information technology, internal operations, relationships, and information sharing significantly impacted inventory turnover performance. We concluded that businesses should boost their internal performance by reducing non-value-added operations and unnecessary inventories for maintaining acceptable productivity. This required productivity can be achieved through the effective implementation of information technology, such as ERP systems. It provides information on receipt of goods, movement within and between locations, sale, removal, or disposal of goods, lot and serial tracking, accurate valuation, and status of goods remaining in inventory at any point in time in all operational activities. Based on this following hypothesis has been developed.

H3: There is a significant impact of ERP implementation on inventory turnover.

\section{OUTPUT-INPUT RATIO}

Beheshti and Beheshti (2010) considered the effective use of organizations' resources and evaluated it by the staff, business, or industry's performance. Focusing on efficiency alone, however, can be detrimental to the organization's long-term success and competitiveness. The maximum advantages of productivity enhancement interventions are understood as productivity is analyzed from two perspectives: the working quality (output/input) of the particular worker or business entity and the success (effectiveness) of the end-user or consumer satisfaction. Over the years, corporations have adopted new technology to integrate business activities to achieve efficiency and effectiveness in their operations. In recent years, we also observed that several businesses have engaged in the ERP to consolidate their corporate functions into a centralized structure. The introduction of ERP helps the organization reduce the sector's operating costs and increase its efficiency, consumer loyalty, and profitability. Based on that, the following hypothesis has been developed.

H4: There is a significant influence of ERP implementation on output/input ratio.

\section{WAREHOUSE COST}

Dealing with issues related to the ERP implementation, Rizzi and Zamboni (1999) argued that the ERP improves the efficiency of internal warehouse logistics. Specifically, they noted that the mere execution of an integrated warehouse management information system does not guarantee warehouse logistics optimization. Instead, to improve the overall design's efficiency, it is necessary to combine the implementation of the ERP with the redesign and reorganization of warehouse logistics and processes. Their research concluded that to create a beneficial synergistic impact and thereby efficiently improve the operations' performance, all of these steps must be done at the same time, grounding on the reorganization and reconstruction process on the execution of the tests. Based on the above argument, the following hypothesis is formulated.

H5: There is a significant influence of ERP implementation on warehouse cost.

\section{PROFITABILITY}

Profitability is measured in terms of Gross Profit Margin (GPM) as the ERP is mainly implemented in the production areas of BSRM. GPM is applied to determine an organization's financial stability and economic progress by reporting the margin leftover from revenues by deducting the cost of goods sold. Hunton et al. (2003) examined the longitudinal impact of ERP adoption on firm performance. They found significantly better profitability over three years for adopters, as compared to non-adopters of ERP. Their results were also consistent with Poston and Grabski (2001), who reported the financial performance of non-adopters decreased over time while it held steady for adopters. Hence, the following hypothesis is formulated.

H6: There is a significant influence of ERP implementation on financial performance. 


\section{METHODOLOGY}

\section{Research Method and Approach}

For this study, the quantitative research method has been employed. The quantitative research approach is related to discovering proof to either support or reject a theory defined in the earlier phases of the study. Thus, the study correctly adopts the deductive approach of research to examine the effect of the ERP adoption on the productivity and profitability of BSRM Steels Limited.

\section{Variables of the Study}

For this research, seven (07) variables have been considered based on an extensive literature survey. The impact of ERP implementation on the company's productivity and profitability is evaluated by considering the performances of the company for pre and post ERP implementation periods. The variables and their sources are given in the table below.

Table 1. Types and Sources of Variables Selected

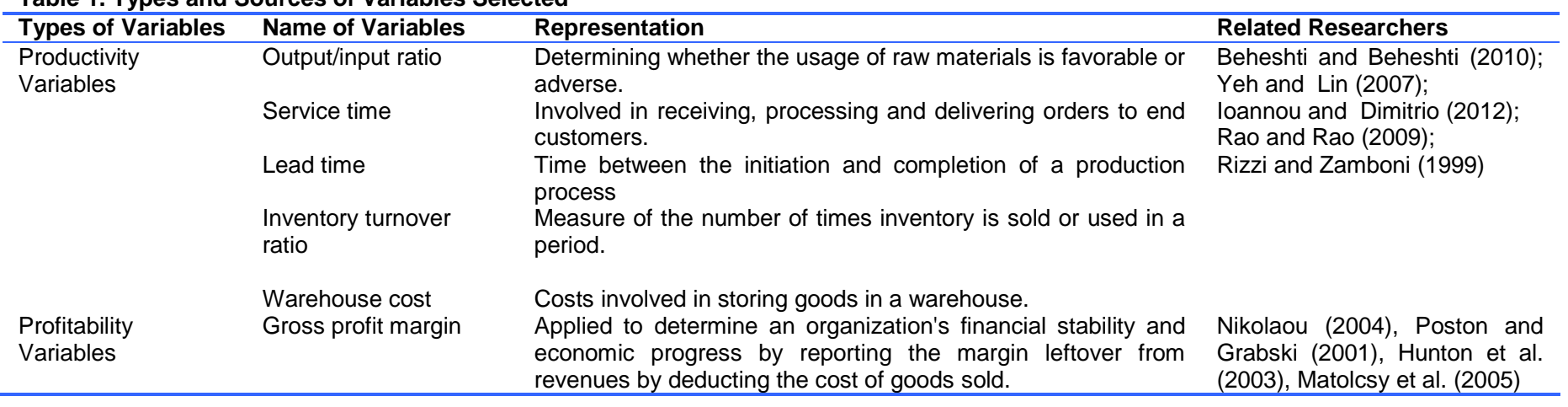

\section{Data Sources}

The study has been conducted by analyzing secondary data. The required secondary data were collected from BSRM Steels Ltd.'s annual reports for 10 years ranging from 2010 to 2019 .

\section{Data Analysis}

Paired sample t-tests have been applied in this research process, concentrating on the pre and post periods of ERP implementation to measure the financial and productivity performance. Data of 10 years period (2010-2019) have been used. The research focuses on the pre-ERP adoption period (2010-2014) and post-ERP adoption period (2015-2019) for evaluation.

\section{RESULTS AND DISCUSSIONS}

\section{Descriptive Statistics}

Table 2. Descriptive Statistics

\begin{tabular}{|c|c|c|c|c|c|}
\hline & $\mathbf{N}$ & Minimum & Maximum & Mean & Std. Deviation \\
\hline Service Time Before & 5 & 3.50 & 4.00 & 3.8000 & .27386 \\
\hline Service Time After & 5 & 1.00 & 3.00 & 1.8000 & .75829 \\
\hline Lead Time Before & 5 & 3.40 & 3.44 & 3.4240 & .01517 \\
\hline Lead Time After & 5 & 2.94 & 3.45 & 3.1940 & .25006 \\
\hline Inventory Turnover Before & 5 & 3.42 & 6.37 & 5.1060 & 1.16410 \\
\hline Inventory Turnover After & 5 & 3.34 & 4.69 & 4.0380 & .49545 \\
\hline Output Input Ratio Before & 5 & 78.87 & 84.12 & 82.2720 & 2.30151 \\
\hline Output Input Ratio After & 5 & 83.51 & 101.13 & 93.7700 & 7.09256 \\
\hline Warehouse Cost Before(Crore) & 5 & 449.63 & 1253.72 & 826.0120 & 356.11054 \\
\hline Warehouse Cost After (Crore) & 5 & 411.47 & 1097.86 & 663.7400 & 273.54668 \\
\hline Gross Profit Margin Before & 5 & 4.94 & 8.97 & 7.2180 & 1.72156 \\
\hline Gross Profit Margin After & 5 & 8.27 & 14.00 & 11.5840 & 2.40105 \\
\hline
\end{tabular}

Table 2 above showed maximum, minimum, and the standard deviation obtained from the variables. The average service time has decreased drastically to 1.80 from 3.80 after the ERP implementation, confirming radical improvement in customer service. The average lead time has slightly reduced after the ERP implementation (3.1940) than before implementing ERP (3.4240), confirming that ERP has facilitated the delivery time, which is also a positive sign. The inventory turnover ratio was higher before implementing ERP (5.1060) than after its application (4.0380), indicating that there is a reduction in turnover. The reason might be the cost savings in terms of cost of goods sold. Productivity (measured by output-input ratio) has increased after the implementation of ERP (93.7700) than before the adoption of ERP (82.2720), concluding that ERP has increased productivity. Warehouse Cost has decreased significantly after the ERP implementation at (663.74), while it was (826.01) before the ERP implementation, concluding that ERP help to reduce the warehouse cost. Finally, the average gross profit margin is higher after implementing ERP, which is 11.58 , while it was 7.21 before the implementation of ERP. It indicates that ERP helps to improve profitability. 


\section{Test of Hypotheses}

The hypotheses formulated earlier are testes with paired t-statistics. Table 3 below shows the details of the test.

Table 3. Paired Samples Test.

\begin{tabular}{|c|c|c|c|c|c|c|}
\hline & \multicolumn{4}{|c|}{ Paired Differences } & \multirow{3}{*}{ 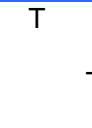 } & \multirow{3}{*}{$\begin{array}{l}\text { Sig. } \\
(2- \\
\text { Tailed) }\end{array}$} \\
\hline & \multirow[t]{2}{*}{ Mean } & \multirow[t]{2}{*}{$\begin{array}{l}\text { Std. Error } \\
\text { Mean }\end{array}$} & \multicolumn{2}{|c|}{$\begin{array}{l}95 \% \text { Confidence Interval } \\
\text { of the Difference }\end{array}$} & & \\
\hline & & & Lower & Upper & & \\
\hline Pair 1Service Time Before - Service Time After & 2.00000 & 27386 & -1.23964 & 2.76036 & 7.3034 & .002 \\
\hline Pair 2Lead Time Before - Lead Time After & .23000 & .11649 & -.09343 & .55343 & 1.9744 & .120 \\
\hline Pair 3Inventory Turnover Before - Inventory Turnover After & 1.06800 & .59439 & -.58228 & 2.71828 & 1.7974 & 147 \\
\hline Pair 4Productivity Before - Productivity After & 11.49800 & 2.30780 & 17.90549 & 5.09051 & 6.9824 & 4.003 \\
\hline Pair 5Warehouse Cost Before - Warehouse Cost After & 162.27200 & 259.98760 & -559.56930 & 884.11330 & .6244 & 4.566 \\
\hline Pair 6Gross Profit Before - Gross Profit After & 4.36600 & 1.44181 & 8.36910 & .36290 & 6.0284 & .004 \\
\hline
\end{tabular}

\section{SERVICE TIME BEFORE AND AFTER EPR IMPLEMENTATION}

From Table 3 , it is seen that the service time variable has a p-value less than 0.05 ( $<<0.05)$, which indicates the acceptance of the alternative hypothesis at a 5\% level of significance, marking a significant influence of ERP on service time provided to customers. The mean service time is higher (3.80) before the implementation of ERP than after the implementation (1.80) ( see Table 2). Hence, it can be concluded that ERP has decreased the service time of customer delivery of BSRM Steels Limited, showing more efficiency in providing services to the customers.

\section{LEAD TIME BEFORE AND AFTER}

From Table 3 , it is seen that the lead time variable has a p-value less than $0.05(\mathrm{p}<0.05)$, which indicates the rejection of alternative hypotheses at a 5\% level of significance, confirming no statistically significant impact of ERP implementation on lead time. However, the mean lead time is higher (3.4240) before the implementation of ERP than after the implementation (3.1940) (see Table 2). Hence, it can be concluded that ERP has improved the lead time efficiency of BSRM Steels Limited though statistically insignificant.

\section{INVENTORY TURNOVER RATIO BEFORE AND AFTER}

The inventory turnover ratio taken for the study has a p-value greater than 0.05 (p $>0.05$ ) (see Table 3 ), showing that the alternative hypothesis can be rejected. It means that ERP has no statistically significant impact on inventory turnover, although the inventory cost has been reduced after ERP implementation.

\section{Productivity (Output-Input Ratio) Before and After}

From Table 3, it is seen that the output-input ratio has a p-value less than 0.05 ( $\mathrm{p}<0.05)$, which indicates the acceptance of the alternative hypothesis at a 5\% level of significance. Thus, there is a significant influence of ERP on productivity. Since the mean is higher (93.7700) after implementing ERP than before the implementation (82.2720), it can be concluded that ERP has increased the productivity of BSRM Steels Limited.

\section{WAREhouse Cost Before aNd After}

Warehouse cost for the study has a p-value greater than 0.05 (p $>0.05$ ) (see Table 3) shows that the alternative hypothesis has been rejected, indicating no statistically significant impact of ERP implementation on warehousing cost. However, the warehouse cost has been reduced after the implementation of ERP (see Table 2).

\section{Gross Profit Before AND AFter}

From Table 3, it is seen that the gross profit margin has a p-value of 0.04, suggesting the acceptance of the null hypothesis at a $5 \%$ level of significance. Hence, there is a significant influence of ERP on gross profit margin. Since the mean gross profit margin is higher (11.5840) after implementing ERP than before the implementation (7.2180), it can be concluded that ERP has increased the profitability of BSRM Steels Limited.

\section{CONCLUSION}

The study is conducted to evaluate the impact of ERP implementation on productivity and profitability in the largest steel manufacturing company in Bangladesh called BSRM Steels Limited. Empirical data results have found general support in favor of it. Overall, it is found that the implementation of ERP has yielded substantial benefits for BSRM Steels Ltd.

Based on the study, the overall productivity (output-input ratio) has shown a positive result, which is consistent with the findings of Beheshti \& Beheshti (2010). The effects of ERP implementation on the productivity is confirmed by the tests performed on the productivity of the plant. There is an average increase of roughly $25 \%$ in production (in quantity terms) from the pre ERP period to post ERP period. Among the other productivity-related variables, service time has shown a significant improvement. Thus, the finding of Yeh \& Lin (2007) can be referred to support this finding. In the pre ERP period, the number of customer sales orders handled on an average was 26000 orders. On the other hand, in the post-ERP period, the customer sales orders handling capacity increased to 50000 customer orders, which is nearly two times. In the post ERP period, the company brought efficiency in handling the customer orders and delivering the product at the right time as per customer needs. Market dynamics are continuously changing, and ERP enables the company to handle this smooth transition. It also brings intangible benefits in the form of reducing manual work.

The lead time has slightly decreased after the ERP implementation though statistically insignificant. However, Ioannou \& Dimitrio (2012) found a significant change in lead time after ERP implementation. The average sales and production (in quantity terms) have increased by $21 \%$ 
and $25 \%$ in the post ERP period. ERP adoption made stock transfers to warehouses from factories and from the warehouse to customers efficiently and systematically. It enabled keeping the optimum level of stock at warehouses based on the regional demand. It helped utilize the warehouse capacity in a maximum manner, leading to decreased warehouse cost after the implementation of ERP; despite the cost reduction, the variable is statistically insignificant.

The profitability variable called Gross Profit Margin had an increase in post ERP implementation. It is statistically significant and consistent with the findings of Hunton et al. (2003). The result is also in accord with the study of Poston and Grabski (2001).

\section{RECOMMENDATIONS AND POLICY IMPLICATIONS}

BSRM Steels Limited has initially adopted ERP for some specific areas, which were deemed necessary then. Seeing the benefits, they can now choose Oracle modules concerning Project Management, which can handle expansion and on-going projects and reduce operational costs concerning the company's plans as the company is going for a rapid increase in the future. The company is currently using its own developed and customized HR software; it can also adopt an HR ERP module that will further integrate data and information with the business modules and reduce time and effort and bring value additions. The other manufacturing companies can also initiate ERP to ensure better management taking the success case of BSRM Steels Ltd. as an example.

BSRM Steels Ltd. has implemented the inventory module and has got substantial benefits; the benefits can further multiply if the company starts using the Vital, Essential, and Desirable (VED) analysis feature in the module at full. VED feature helps in classifying stocks with criticality and non-criticality and will further help reduce the company's inventory holding cost. The company can also declare obsolete items in the ERP system, which will enable the company to reduce the value of the unnecessary stock by realizing the market value for it. BSRM can take the advantage of applying the activity based costing (ABC) analysis in the ERP inventory module feature, strengthening overall inventory management. It is also essential for other steel manufacturers to try to minimize wastage by adopting such technologies.

BSRM can further adopt the ERP module whereby the company can prepare consolidated financial accounts for the entire group. It may impact all the stakeholders, and can improve overall profitability and return on equity for the shareholders and the company. It can also help the group through better access to international financial markets. Moreover, it will ensure transparency and easy tax management.

The government may take policy initiative in terms of tax benefits and others to motivate steel manufacturers in implementing ERP. Such an action will help the country's economic growth through increased productivity. At the same time, a transparent financial and accounting system will help tax collection and administration.

There are some drawbacks to the study that need to be acknowledged. First, this analysis's key emphasis was on ERP adoption only in the leading steel manufacturing company in Bangladesh. Thus, similar studies can also be adapted for further analysis in other companies. Second, this analysis has a relatively lower number of profitability variables, indicating a more detailed examination could be considered with more financial variables. Studies can also be undertaken for a cross-company comparison. Further research can be initiated involving specific considerations such as the investment management for ERP implementation, determinants of ERP for manufacturing industries, and barriers in adopting ERP. Studies can also be done in other manufacturing industries like pharmaceuticals and textile industries.

\section{References:}

Bagranoff, N. A., \& Brewer, P. C. (2003). PMB investments: An enterprise system. Journal of Information Systems, 17(1), 85-106.

Bangladesh Steel Industry Review. (2016). EBLSL Research Team.

Beheshti, H. M., \& Beheshti, C. M. (2010). Improving productivity and firm performance with enterprise resource planning. Enterprise Information Systems, 4(4), 445-472.

Brazel, J. F., \& Dang, L. (2008). The effect of ERP system implementations on the management of earnings and earnings release dates. Journal of information systems, 22(2), 1-21.

Hasan, A. M., Hoq, M. T., \& Thollander, P. (2018). Energy management practices in Bangladesh's iron and steel industries. Energy strategy reviews, $22,230-236$.

Hayes, D. C., Hunton, J. E., \& Reck, J. L. (2001). Market reaction to ERP implementation announcements. Journal of Information systems, 15 (1), 3-18.

Hunton, J. E., Lippincott, B., \& Reck, J. L. (2003). Enterprise resource planning systems: comparing firm performance of adopters and non-adopters. International Journal of Accounting information systems, 4(3), 165-184.

Ioannou, G., \& Dimitriou, S. (2012). Lead time estimation in MRP/ERP for make-to-order manufacturing systems. International Journal of Production Economics, 139(2), 551- 563.

Kallunki, J. P., Laitinen, E. K., \& Silvola, H. (2011). Impact of enterprise resource planning systems on management control systems and firm performance. International Journal of Accounting Information Systems, 12(1), 20-39.

LightCastle Partners, [Online]. Available: https://www.lightcastlebd.com/insights/ 2016/02/market-insight-emerging-steel-industry-in-bangladesh. [Accessed 3 August 2020].

Matolcsy, Z. P., Booth, P., \& Wieder, B. (2005). Economic benefits of enterprise resource planning systems: some empirical evidence. Accounting \& Finance, 45(3), 439-456.

Nicolaou, A. I. (2004). Firm performance effects in relation to the implementation and use ofenterprise resource planning systems. Journal of information systems, $18(2), 79-105$

Nicolaou, A. I., \& Bhattacharya, S. (2006). Organizational performance effects of ERP systems usage: The impact of post-implementation changes. International Journal of Accounting Information Systems, 7(1), 18-35.

Olhager, J., \& Selldin, E. (2003). Enterprise resource planning survey of Swedish manufacturing firms. European Journal of Operational Research, 146(2), 365373.

O'Leary, D. E. (2004). Enterprise resource planning (ERP) systems: an empirical analysis of benefits. Journal of emerging Technologies in Accounting, 1(1), 6372.

Poston, R., \& Grabski, S. (2000). The impact of enterprise resource planning systems on firm performance. ICIS 2000 Proceedings, 48.

Poston, R., \& Grabski, S. (2001). Financial impacts of enterprise resource planning implementations. International Journal of Accounting Information Systems, 2(4), 271-294

Rao, C. M., \& Rao, K. P. (2009). Inventory turnover ratio as a supply chain performance measure. Serbian Journal of Management, 4(1), 41-50.

Rizzi, A., \& Zamboni, R. (1999). Efficiency improvement in manual warehouses through ERP systems implementation and redesign of the logistics processes. Logistics Information Management, 12(5), 367-377.

Ross, J. W., \& Vitale, M. R. (2000). The ERP revolution: surviving vs. thriving. Information systems frontiers, 2(2), $233-241$.

Saharia, A., Koch, B., \& Tucker, R. (2008). ERP systems and internal audit. Issues in Information Systems, 9(2), 578-586.

Velcu, O. (2007). Exploring the effects of ERP systems on organizational performance: evidence from Finnish companies. Industrial Management \& Data Systems, 107(9), 1316-1334.

Yeh, T. M., Yang, C. C., \& Lin, W. T. (2007). Service quality and ERP implementation: A conceptual and empirical study of semiconductor-related industries in Taiwan. Computers in Industry, 58(8-9), 844-854. 